https://doi.org/10.15407/ujpe64.5.442

O.V. MAKARENKO, L.V. POPERENKO, O.I. ZAVALISTYI, A.L. YAMPOLSKIY

Taras Shevchenko National University of Kyiv, Faculty of Physics, Chair of Optics

(64/13, Volodymyrs'ka Str., Kyiv 01601, Ukraine; e-mail: uv365nm@ukr.net)

\title{
ELLIPSOMETRIC DIAGNOSTICS OF A TRANSIENT SURFACE LAYER IN OPTICAL GLASS
}

\begin{abstract}
Optical properties of a transient layer with a broken structure that arises at the surface of optical glass at its treatment have been considered. Rather often, the surface of optical elements is considered to be perfect, although the actual inhomogeneous surface structure can have a significant effect for precision physical experiments or novel technological problems. Furthermore, the simulation of the surface layer structure and the corresponding optical characteristics, as well as the study of a possibility to determine those parameters from the results of optical researches, is also of theoretical interest, which is demonstrated in this work. Ellipsometric measurements of optical glass specimens with a broken surface layer are carried out. When modeling the angular dependences of the ellipsometric parameters $\tan \psi$ and $\cos \delta$, the nearsurface specimen region is considered as a stack of 500 thin layers, and the matrix method of light reflection in this structure with regard for the interference phenomenon is used in calculations. Five models are tested for the optical profile of a nonuniform layer, whose parameters are fitted to achieve the minimum of the target function describing the discrepancy between the calculated and measured data. It is found that the theoretical models describe the optical properties of the specimens more accurately, if they make allowance for the inhomogeneous surface layer. Nevertheless, the solution of the inverse ellipsometric problem turns out ambiguous, so that additional measurements are required for the final choice of a model that would be adequate to the actual morphological structure of the broken layer to be made. However, the key advantage of the applied method consists in that it allows a direct registration of the optical response of the system.
\end{abstract}

Ke ywords: ellipsometry, glass, inhomogeneous layer, optical profile.

\section{Introduction}

A considerable body of works were devoted to the inspection of the quality of optical layers on the glass and dielectric surface. Besides a purely applied aspect associated with the influence of surface layers on the optical properties of surfaces (e.g., the surfaces of intracavity elements in ionic and excimer lasers [1], gradient optical elements [2-4], optical contacts $[5,6]$, and lightening coatings [3]), a considerable scientific

(c) O.V. MAKARENKO, L.V. POPERENKO,

O.I. ZAVALISTYI, A.L. YAMPOLSKIY, 2019 442 interest consists in elucidating the structural features and the peculiarities in the optical response of those layers. This task can only be fulfilled by combining and comparing the results obtained by various methods, such as ellipsometry, Auger spectroscopy, profilometry, layer-by-layer etching, and others $[2,7,8]$.

The advantages of the ellipsometric method, when studying a solid surface, consist in that it is nondestructive, its implementation is relatively simple, and it is very sensitive to structural changes in the surface layer. However, in any case, this method requires the application of some assumptions and a cor-

ISSN 2071-0194. Ukr. J. Phys. 2019. Vol. 64, No. 5 
responding theoretical model. At the same time, it does not guarantee the uniqueness and unambiguity of the solution obtained. An inadequacy of the model chosen for the surface layer invokes difficulties, when solving the inverse problem of ellipsometry [9]. Therefore, a challenging task in such researches is a more detailed elucidation of the issues concerning the homogeneity of the surface layer, the determination of its thickness, and the distribution of the refractive index across the layer thickness. Taking all that factors into account, this work is aimed at solving the inverse ellipsometric problem for an optical glass specimen with a certain transient layer at its surface, as well as comparing the calculation results obtained in the framework of a few assumptions about the morphology of the surface layer and using a few theoretical models of its structure.

\section{Experimental Part}

For researches in this work, we selected optical glass specimens fabricated in the form of optical prisms with polished faces. At the first stage of the experiment, the prism refraction indices were determined. In so doing, the prisms were considered as massive material (glass) objects. The goniometric method was used to determine the least deviation angle for a beam passed through a prism [10]. This method is typical of similar problems and provides an accuracy not worse than $0.01 \%$. The results obtained were in good agreement with the passport valuesfor the applied glass brands (see Table 1).

At the second stage of the experiment, an automated goniopolarimetric device described in work [11] was used to perform ellipsometric measurements of light reflected from the polished prism surface. As a result, the dependences of the restored linear polarization azimuth $\psi$ and the phase shift $\Delta$ between the $p$ - and $s$-components of reflected light on the incidence angle $\theta$ at the external prism face were determined. The measurements were carried out according to the Polarizer-Sample-Analyzer (PSA) scheme, by using the rotating-analyzer method. A light source with the radiation wavelength $\lambda=625 \mathrm{~nm}$ and the full width at half-maximum (FWHM) of the corresponding band equal to $10 \mathrm{~nm}$ was applied.

\section{Theoretical Background}

While solving the problem concerned, it was necessary to select a physical model for the researched object and to solve an inverse ellipsometric problem together with the optimization of its parameters. In ellipsometry, as well as in other optical methods, the adequacy of a model describing the reflecting system of the examined object is estimated on the basis of the maximum likelihood principle with the help of the target function $F\left(\Delta^{\exp }, \psi^{\exp }, \Delta^{\text {theor }}, \psi^{\text {theor }}, m\right)$, whose values depend not only on the experimental and theoretical (calculated) data obtained for the studied reflection system, but also on the type of a model chosen for the surface layer with the refractive index $n_{m}(z)$, where $m=1 \div 5$ marks our theoretical models [1]. In particular, in this work, the following target function was used:

$$
\begin{aligned}
& F=\frac{1}{M} \sum_{j=1}^{M}\left[\left(\cos \Delta_{j}^{\text {theor }}-\cos \Delta_{j}^{\exp }\right)^{2}+\right. \\
& \left.+\left(\tan \psi_{j}^{\text {theor }}-\tan \psi_{j}^{\text {exp }}\right)^{2}\right]
\end{aligned}
$$

where $M$ is the number of experimental measurements.

The procedure of polishing the optical components following a standard technology and their mechanical processing give rise to the formation of a surface layer with a broken structure. Furthermore, this structure is deformed and stressed, with parameters which differ from those in the bulk $[5,6]$. In order to avoid damages, the thermal annealing of specimens is often carried out. Therefore, when performing the ellipsometric analysis, the following mathematical description of the optical profile is used [1]:

$\varepsilon(z)=\varepsilon_{1}+\left(\varepsilon_{0}-\varepsilon_{1}\right) f_{m}(q z)$,

where $q=1 / d$ is a characteristic reciprocal thickness of the surface layer, $\varepsilon_{0}$ the dielectric permittivity at the interface "external medium-surface layer", $\varepsilon_{1}$ the dielectric constant in the glass bulk, and $f_{m}(q z)$ a characteristic function corresponding to the $m$-th

Table 1. Experimentally measured refractive indices of optical glass specimens

\begin{tabular}{|c|c|c|}
\hline Specimen & Glass brand & $\begin{array}{c}\text { Refractive index } n \\
(\lambda=625 \mathrm{~nm})\end{array}$ \\
\hline Prism 1 & F1 & 1.610 \\
Prism 2 & TF3 & 1.713 \\
Prism 3 & K8 & 1.515 \\
\hline
\end{tabular}




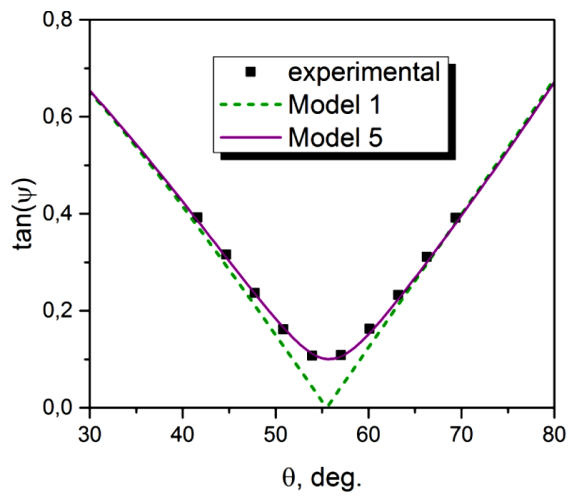

$a$

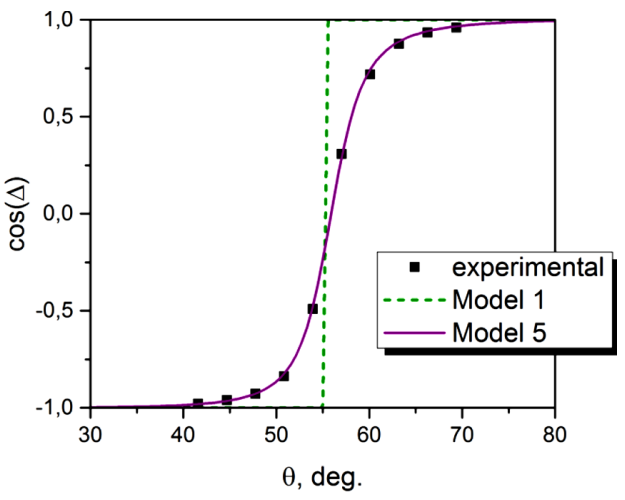

$b$

Fig. 1. Experimental and calculated angular dependences of the ellipsometric parameters $\tan \psi($ panel $a)$ and $\cos \Delta($ panel $b)$ for a specimen of optical glass TF3 (Prism 2)

model. The dielectric permittivities $\varepsilon_{i}$ are related to the corresponding refractive indices $n_{i}$ through the relation $n_{i}=\operatorname{Re} \sqrt{\varepsilon_{i}}(i=0,1)$.

In this work, the following models are tested:

1) an optically homogeneous glass specimen without any surface layer, i.e. $f_{1}(q z)=0$; the specimen is characterized by a single refractive index value $n_{1}$;

2 ) an optically homogeneous effective surface layer on the substrate, so that $f_{2}(q z)=1$ at $0<z<d$;

3) an inhomogeneous surface layer, whose refractive index changes linearly with the depth: $f_{3}(q z)=(1-$ $-q z)$ at $0<z<d$

4) an inhomogeneous surface layer, whose refractive index changes exponentially with the depth: $f_{4}(q z)=\exp (-q z)$ at $0<z<\infty$;

5) an inhomogeneous surface layer, whose refractive index changes nonmonotonically with the depth following the characteristic function $f_{5}(q z)=(1-$ $-q z) \exp (-q z) 0<z<\infty$.

For models 2 to 5 , the value of the glass refractive index should asymptotically approach the standard (passport) value for the corresponding glass brand (see Table 1), as the distance from the specimen surface into the depth increases. It should be emphasized that it is exactly the bulk index of refraction that is given by the method of the refractive index measurement on the basis of the least deviation angle, because, according to the refraction law, the layers on the glass surface do not affect the inclination of the beam propagating through them. However, we emphasize that, in the spectroscopy of a violated total internal reflection, the value of the refractive in- dex in the surface layer has to be properly taken into account.

The theoretical calculation of the dependences $\psi(\theta)$ and $\Delta(\theta)$ is carried out using the matrix method, which is applied to the calculation of optical characteristics at the light transmission through multilayer systems and which was described in work [12] in detail. This method is based on determining the stationary amplitudes of the electric field strength at the medium interfaces with regard for the phenomenon of wave interference at multiple reflections.

The near-surface layer in optical glass specimens is modeled as a stack of $(k=500)$ thin layers, whose parameter values were assigned in accordance with five models described above. In this approach, the dependences $\psi(\theta)$ and $\Delta(\theta)$ are calculated, as well as the values of the target function $F$ that describes the deviations of those dependences from the experimental data. The parameters of each model are optimized by minimizing the value of the function $F$. As a result, the required profile of the refractive index variation with the specimen depth is obtained.

\section{Results and Their Discussion}

The dependences of the quantities $\tan \psi$ and $\cos \Delta$ on the probing-beam incidence angle $\theta$, both experimentally measured and obtained as the result of simulations, are depicted in Fig. 1. Since they turned out similar to each other, the corresponding dependences for prism 2 only are exhibited as a typical example. Moreover, since the difference between the corresponding curves for models 2 to 5 is visually in-

ISSN 2071-0194. Ukr. J. Phys. 2019. Vol. 64, No. 5 

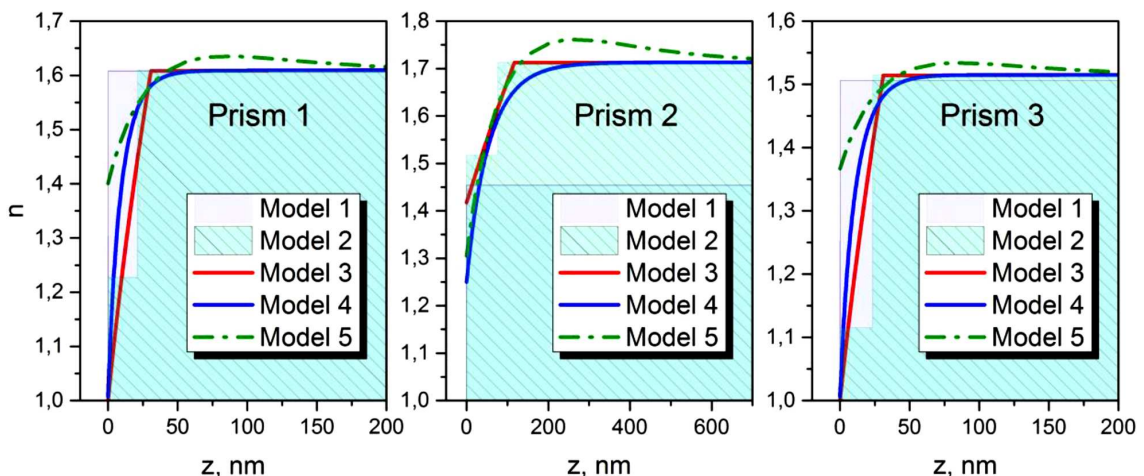

Fig. 2. Profiles of the refractive index $n$ along the depth $z$ of optical glass samples F1 (Prism 1), TF3 (Prism 2), and K8 (Prism 3) calculated for various theoretical models

significant, only curves for models 1 and 5 are shown for the sake of comparison.

As one can see from Fig. 1, the dependence $\psi(\theta)$ does not reach zero in a vicinity of the Brewster angle $\theta=55^{\circ}$. This fact testifies to a residual ellipticity of the reflected light, which does not correspond to the light reflection from a perfect air-glass interface described by the Fresnel formulas. Such a behavior of the dependence $\psi(\theta)$ and the corresponding interval $\Delta \theta$ (a spread of the incidence angles, within which the phase falls from $\pi$ to 0 ) completely characterize the optical response of the surface layer.

The refractive-index profiles calculated for three optical glass specimens in the framework of the above-mentioned theoretical models are depicted in Fig. 2. The corresponding thicknesses $d$ of the surface layers, the initial refractive indices $n_{\text {start }}$, and the values of the target function $F$ are summarized in Table 2. For models 3 to 5 , the thickness $d$ of the surface layer is considered to be equal to the depth $z$, at which the refractive index differs by $0.5 \%$ from the corresponding final value quoted in Table 1 . The initial refractive index $n_{\text {start }}$ is ascribed to the first of 500 layers that simulates the near-surface optical glass region. In model $2, n_{\text {start }}$ corresponds to the refractive index of the effective layer. In the course of calculations, the space increment was so selected that the total depth occupied by the indicated 500 layers would almost correspond to the given thickness $d$.

When analyzing the results obtained, one can see that model 1 is the worst for the description of the optical properties of specimens, because the corresponding value of the target function $F$ is the largest. We should emphasize at once that this fact confirms our assumption about the presence of a transient layer, whose optical parameters differ from the bulk values, at the optical glass surface. The most different is the result of model 1 for prism 2: the refractive index turned out significantly underestimated. This circumstance can be explained by the influence of a chemical component used for the treatment of the glass surface on it (more intensive glass leaching),

Table 2. Results of theoretical simulation of surface layers in optical glass specimens

\begin{tabular}{|c|c|c|c|}
\hline Specimen & Prism 1 & Prism 2 & Prism 3 \\
\hline Model 1 & & & \\
$F(m=1)$ & $3.08 \mathrm{e}-2$ & $8.86 \mathrm{e}-2$ & $4.08 \mathrm{e}-2$ \\
$d, \mathrm{~nm}$ & - & - & - \\
$n_{\text {start }}$ & 1.608 & 1.454 & 1.505 \\
Model 2 & & & \\
$F(m=2)$ & $2.06 \mathrm{e}-4$ & $3.01 \mathrm{e}-4$ & $1.68 \mathrm{e}-4$ \\
$d, \mathrm{~nm}$ & 20.7 & 76.0 & 22.9 \\
$n_{\text {start }}$ & 1.227 & 1.518 & 1.115 \\
$\eta$ & 0.39 & 0.74 & 0.24 \\
Model 3 & & & \\
$F(m=3)$ & $2.51 \mathrm{e}-4$ & $2.58 \mathrm{e}-4$ & $4.35 \mathrm{e}-4$ \\
$d, \mathrm{~nm}$ & 30.3 & 113.4 & 30.6 \\
$n_{\text {start }}$ & 1.001 & 1.418 & 1.001 \\
Model 4 & & & \\
$F(m=4)$ & $8.21 \mathrm{e}-4$ & $2.31 \mathrm{e}-4$ & $2.03 \mathrm{e}-3$ \\
$d, \mathrm{~nm}$ & 44.4 & 234.7 & 49.2 \\
$n_{\text {start }}$ & 1.008 & 1.250 & 1.006 \\
Model 5 & & & \\
$F(m=5)$ & $2.29 \mathrm{e}-4$ & $2.19 \mathrm{e}-4$ & $1.94 \mathrm{e}-4$ \\
$d, \mathrm{~nm}$ & 189.8 & 686.4 & 170.4 \\
$n_{\text {start }}$ & 1.400 & 1.305 & 1.367 \\
\hline
\end{tabular}


which manifests itself extremely strongly in the case of heavy flint glasses including TF3. Models 2 to 5 are better, and the difference between the minimum values of the target error function $F$ is insignificant for them. However, the corresponding layer thicknesses differ considerably: this parameter amounts to about 200-700 nm for model 5 and about 20-200 nm for models 2 to 4 . Furthermore, the corresponding $n_{0}$ values are also different. In this connection, there arises a problem concerning the adequacy of the selected models to the actual specimen structure and a necessity to make certain corrections to them.

In a number of works, some variants for the structure of a rough surface layer were considered. For instance, a model of effective layer on silicon was analyzed in work [13]. The cited authors considered the specimen surface to be rough, and the transient layer as a mixture that is partially filled with air and partially with silicon. In the framework of the Bruggemann effective-medium model, the corresponding fractions of those media in the layer are described by filling factors. In the simplified case of two-component effective layer, we have the following relation [14]:

$\eta \frac{\varepsilon_{1}-\varepsilon^{\mathrm{eff}}}{\varepsilon_{1}+2 \varepsilon^{\mathrm{eff}}}+(1-\eta) \frac{\varepsilon_{0}-\varepsilon^{\mathrm{eff}}}{\varepsilon_{0}+2 \varepsilon^{\mathrm{eff}}}=0$,

where $\eta$ is the filling factor of glass in the effective layer, and $\varepsilon_{1}, \varepsilon_{0}$, and $\varepsilon^{\text {eff }}$ are the dielectric constants of glass, medium (air), and effective layer, respectively.

The thicknesses of effective layers in glass, which we determined using this approach, are in good agreement with the root-mean-square values for rough surfaces that correspond to the surface finish class from 11 to 13 [15]. The corresponding filling factors $\eta$ for the effective layer are quoted in Table 2.

A three-layer model of the optical glass surface was considered in work [5]. The cited authors associated the surface layer inhomogeneity with the surface roughness, the presence of cracks in it, a certain structural loosing or compacting owing to local deformations or glass leaching at various depths as a result of the chemical-mechanical action on the surface at its treatment.

The variation $n(z)$ of the refractive index with the depth, which was obtained in model 5 , as well as the estimated layer thickness, is in good agreement with the results of works $[1,6,16]$. However, the final answer to the questions concerning more precise parameter values, the optical response of the layer formed at the optical glass surface, its real thickness and homogeneity degree cannot be obtained, of course, only from ellipsometric results. For this purpose, researches with the application of the layer-bylayer etching into the glass depth, as well as auxiliary methods for the analysis of the morphological structure of the optical glass surface, would be pertinent. Under such conditions, the Auger-spectroscopy and profilometry methods would make it possible to ultimately choose a model among the proposed theoretical ones, which would be the most adequate to the real layer morphology. On the basis of conclusions made in works $[1,6]$, model 5 is the most suitable for the layer at the optical glass surface, because it involves the specific features of its formation in the course of glass treatment and when finishing the physico-chemical state of the glass surface to a surface finish class of 13-14 [15].

\section{Conclusions}

With the help of the ellipsometric diagnostics of optical glass specimens, the presence of a transient layer at their surface is detected. This layer emerges as a result of the mechanical treatment and the polishing of a massive glass specimen when manufacturing optical components.

A comparison of the solutions obtained for the inverse problem aimed at the determination of optical characteristics of this layer in five various models testified to the inhomogeneous (layered) structure of the specimens. The calculation results obtained for various profiles of the refractive index along the specimen depth give rise to the values of the surface layer thicknesses that can vary from tens to several hundred nanometers. However, only the results obtained for model 5 with a layer thickness of 190-690 nm are in agreement with the corresponding values for glass surfaces obtained, by using standard treatment methods.

Despite a good consistency of the results describing the optical response of the transient surface layer obtained in model 5 with the data of other fundamental researches, where a nonmonotonic dependence of the response on the specimen depth was found, the ultimate answer to the question concerning the mor- 
phological structure of the transient surface layer requires that precision methods for the analysis of the atomic structure of deep layers should be applied. However, the method of ellipsometric surface diagnostics used in this work has a crucial advantage, if compared with such methods of determination of the morphology and composition of the surface layer as atomic force microscopy and Auger spectroscopy. Namely, our method provides a direct registration of the optical response from the researched structure, whereas the indicated methods make it possible to determine only its morphological structure, but not the optical parameters.

1. A.A. Novikov, I.A. Khramtsovsky, V.Yu. Ivanov, I.S. Fedorov, A. Turkboev. Ellipsometry of inhomogeneous surface layers of anisotropic optical elements. Izv. Vyssh. Uchebn. Zaved. Pribor. 52, 62 (2006) (in Russian).

2. A.A. Novikov, V.T. Prokopenko. Analysis of accurate and approximate methods for solving the reverse problem of ellipsometry for inhomogeneous surface layers. Sci. Techn. J. Inf. Technol. Mech. Opt. 6, 87 (2006) (in Russian).

3. O.D. Volpian. Optical coatings with longitudinal gradient of refraction index and vacuum-plasma technology of their obtaining. Prikl. Fiz. No. 6, 47 (2012) (in Russian).

4. A.N. Gorlyak, I.A. Khramtsovsky, V.M. Solonukha. Ellipsometry method application in optics of inhomogeneous media. Sci. Techn. J. Inf. Technol. Mech. Opt. 15, 378 (2015) (in Russian).

5. A.N. Gorlyak, O.S. Dron, Yu.V. Lisitsyn, A.I. Semenenko. Investigation of disturbed layers of polished optical surface and stresses in adhesive and glueless joints of optical elements by the method of ellipsometry. Sci. Techn. J. Inf. Technol. Mech. Opt. 4, 30 (2004) (in Russian).

6. A.N. Gorlyak, A.G. Novak, V.M. Solonukha, I.A. Khramtsovsky. Optical characteristics definition of optical technology surface elements for their optical connections. Sci. Techn. J. Inf. Technol. Mech. Opt. 13, 62 (2013) (in Russian).

7. A.A. Novikov, V.T. Prokopenko, I.A. Khramtsovsky. Optical properties of the rough surface of optoelectronics elements. Sci. Techn. J. Inf. Technol. Mech. Opt. 15, 73 (2004) (in Russian).

8. A.N. Gorlyak, V.M. Solonukha, I.A. Khramtsovsky. Sectioning method application at ellipsometry of inhomogeneous reflection systems. Sci. Techn. J. Inf. Technol. Mech. Opt. 14, 24 (2014) (in Russian).

9. D.E. Aspnes. Precision bounds to ellipsometer systems. Appl. Opt. 14, 1131 (1975).

10. L.V. Poperenko, V.S. Stashchuk. Fundamentals of Physics of Optotechnique Materials (Kyiv Univ., 2011) (in Ukrainian).

11. A.L. Yampolskiy, O.V. Makarenko, L.V. Poperenko, V.O. Lysiuk. Ellipsometry of hybrid noble metal-dielectric nanostructures. Semicond. Phys. Quant. Electr. Optoelectr. 21, 412 (2018).

12. G. Hass. Physics of Thin Films: Advances in Research and Development (Academic Press, 1963).

13. D.E. Aspnes, J.B. Theeten, F. Hottier. Investigation of effective-medium models of microscopic surface roughness by spectroscopic ellipsometry. Phys. Rev. B 20, 3292 (1979).

14. L.A. Apresian, D.V. Vlasov, D.A. Zadorin, V.I. Krasovskii. On the model of an effective medium for particles with a complex structure. Zh. Tekhn. Fiz. 87, 10 (2017) (in Russian).

15. L.V. Poperenko, Yu.D. Filatov. Optical Surfaces Treatment Technology (Kyiv University Paleographic Centre, 2004) (in Ukrainian).

16. M.E. Aleksandrov, T.M. Danilova, P.S. Belomutskaya, I.A. Khramtsovsky. Radiation loss determination on the optical elements by ellipsometry and impulse photometry methods. Sci. Techn. J. Inf. Technol. Mech. Opt. 11, 9 (2011) (in Russian).

Received 04.04.19.

Translated from Ukrainian by O.I. Voitenko

О.В. Макаренко, Л.В. Поперенко,

О.І. Завалістий, А.Л. Ямпольсъкий

ЕЛІПСОМЕТРИЧНА ДІАГНОСТИКА ПОВЕРХНЕВОГО ШАРУ ОПТИЧНОГО СКЛА

$\mathrm{P}$ е $з$ ю м е

Розглянуто оптичні властивості перехідного порушеного шару на поверхні оптичного скла. Найчастіше поверхні оптичних елементів вважають ідеальними, хоча для точних фізичних експериментів чи новітніх технологічних задач реальна неоднорідна структура поверхні може мати суттєвий вплив. До того ж, моделювання будови поверхневого шару, його оптичних характеристик і дослідження питання про можливість їх знаходження за результатами оптичних досліджень становлять і теоретичний інтерес, що й з'ясовувано у даній роботі. Було проведено еліпсометричні вимірювання зразків оптичного скла, що містять порушений шар. Для моделювання кутових залежностей еліпсометричних параметрів $\tan (\psi)$ i $\cos (\Delta)$ приповерхневу область зразка представляли як послідовність 500 тонких шарів і застосовували матричний метод розрахунку відбивання світла такою структурою із врахуванням явища інтерференції. Було взято 5 моделей оптичного профілю неоднорідного шару, параметри яких оптимізували до досягнення мінімального значення цільової функції відхилення між розрахованими та виміряними даними. Встановлено, що теоретичні моделі з врахуванням неоднорідного шару точніше описують оптичні властивості зразків, але все ж розв'язок оберненої задачі еліпсометрії не є однозначним. I хоча для остаточного вибору моделі, адекватної реальній морфологічній будові порушеного шару, необхідні додаткові вимірювання, ключова перевага використаного методу полягає в тому, що він безпосередньо забезпечує реєстрацію саме оптичного відгуку системи. 